\title{
Vibration Sensor Approaches for the Monitoring of Sand Production in Bohai Bay
}

\author{
Kai Wang, ${ }^{1,2}$ Zhiguo Liu, ${ }^{1,2}$ Gang Liu, ${ }^{3}$ Longtao Yi, ${ }^{1,2}$ \\ Kui Yang, ${ }^{1,2}$ Shiqi Peng, ${ }^{1,2}$ and Man Chen ${ }^{1,2}$ \\ ${ }^{1}$ College of Nuclear Science and Technology, Beijing Normal University, Beijing 100875, China \\ ${ }^{2}$ Beijing Radiation Center, Beijing 100875, China \\ ${ }^{3}$ School of Petroleum Engineering, China University of Petroleum, Qingdao 266580, China \\ Correspondence should be addressed to Zhiguo Liu; liuzhiguo512@hotmail.com
}

Received 10 December 2014; Revised 15 April 2015; Accepted 30 April 2015

Academic Editor: Didier Rémond

Copyright (C) 2015 Kai Wang et al. This is an open access article distributed under the Creative Commons Attribution License, which permits unrestricted use, distribution, and reproduction in any medium, provided the original work is properly cited.

\begin{abstract}
The real-time monitoring of sand production has always been an important issue during the process of oil production in offshore field. This paper illustrates a new alternative vibration sensor approach to monitor the sand production. A special broadband sensor was selected. Then the time-frequency analysis, characteristic sand frequency band filter method, and peak searching-denoising method were proposed to enhance the detection ability of sand vibration signals in strong background noises of crude oil flow. After that, visible differences in time-frequency domain and power spectrum between sand and nonsand production well can be observed. Four typical wells in Bohai oil production platform were selected to investigate the monitoring effects of sand production. The monitoring findings show that there exists a good correlation between the vibration power spectrum amplitude and the sand production volume, which is consistent with actual results.
\end{abstract}

\section{Introduction}

Sand production is a phenomenon that occurs in the petroleum industry during the process of oil production in offshore field. The drilling and petroleum production will redistribute the stresses and pore pressure in sandstone formation. Therefore, sand particles move from the reservoir into the well along with the oil flow. This is commonly known as "sand production" in the petroleum industry $[1,2]$. When the sand production is continuous, the normal well production will be seriously affected due to the partial sand-clogging $[3,4]$. Sanding can also cause damage to facilities such as pipelines and valves [5]. There have been a considerable amount of researches on the mechanism and prediction of sand production [6], but they are not enough to meet the need of oil production. On the other hand, the real-time sand production information can help operator to control the sand production and optimize the well production in a better way. Then the life span of oil well can be extended. Therefore, it is important to develop an effective system for monitoring the sand production information in real-time.

The monitoring of sand production has long been recognized as a challenge by engineers and researchers all around the world. Over the years, a number of monitoring techniques have been developed and proposed to meet some of these difficult challenges. For example, Ibrahim and Haugsdal [7] applied acoustic sand detector to obtain the information of sand in pipeline. Braaten et al. $[8,9]$ used electrical resistance (ER) method to achieve the sand production signals by changing probe resistance, which was caused by particles impact. Hii et al. [10] monitored the particle characteristics in multiphase flow by acoustic emission technology. Despite their availabilities, these sand detection approaches are relatively expensive or make installation and maintenance difficult or impractical. For instance, ER equipment should be installed with invasion of pipeline. Consequently, a new noninvasion vibration sensor approach is explored to realtimely monitor the sand production. 


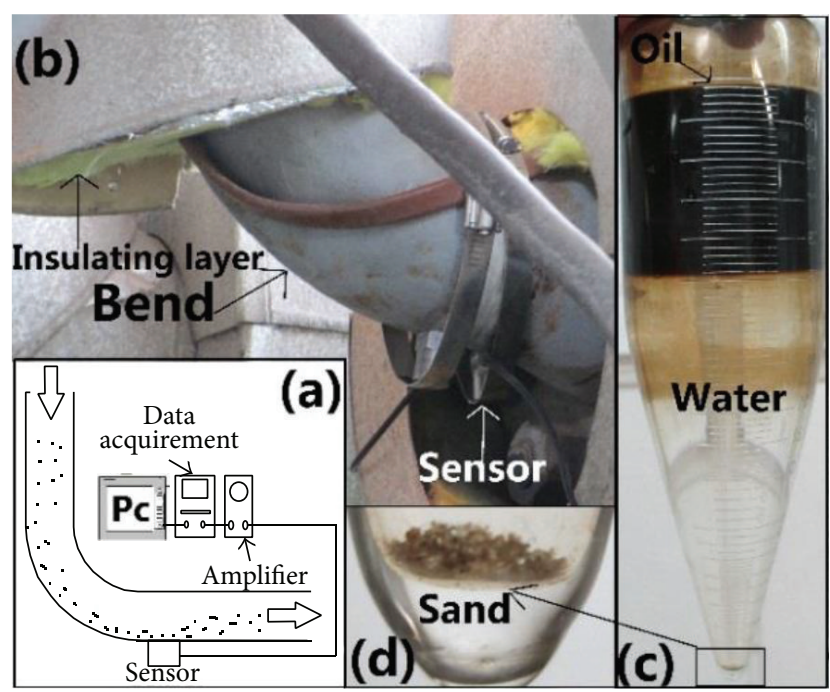

FIGURE 1: Schematic diagram of sand monitoring: (a) illustration of the sand monitoring facility, (b) sensor field installation graph, (c) the $100 \mathrm{~mL}$ crude oil from pipeline after centrifugation, and (d) amplified sand sample.

In this work, a special wideband vibration sensor was selected to obtain the vibration signals caused by sandcarrying flow hitting the pipe wall at bends in the pipeline due to inertia. A set of signal processing methods were used to obtain characteristic signals caused by low concentrations of sand in the flow background noise. Four typical wells in Bohai oil production platform were chosen to investigate the sand production monitoring effects, and the monitoring results showed a good consistency with actual results.

\section{Approaches}

2.1. Sand Production Monitoring Method. The monitoring of sand production is a real-time detection during crude oil transmission in pipeline. On approaching a change in flow direction, sand's inertia causes it to deviate from the streamlines of the carrying fluid, generating vibration signals by particles impingement on the walls of the pipe. Sand does work for bend walls and the impact of kinetic energy will be converted to the strength of vibration. Accordingly, vibration sensor is installed at the downstream bend tube wall within the insulating layer. The design of the monitoring method is illustrated in Figure 1.

Impact vibration signals of oil flow and sand are obtained by the sensor. Short-time Fourier transform (STFT) and frequency domain are selected to obtain the sand impact information in complex crude oil flow with heavy noise. The STFT provides a 2D time-frequency domain for all frequencies contained in the vibration signal, and the magnitude of STFT on the vibration signal $y(t)$ is defined as [11]

$$
\operatorname{TF}(t, f)=\left|\int_{-\infty}^{+\infty} y(\tau) h *(\tau-t) e^{-i 2 \pi f \tau} d \tau\right|,
$$

where $h(t)$ is a short-time analysis window centered at $t=0$. The width of $h(t)$ can distinguish the adjacent frequencies from each other. The STFT reflects the sand and oil flow energy distribution on the time-frequency plane. It is hard to extract characteristic frequencies in lower frequency band because of the great interference background noise caused by mechanical system, such as oil pump and other rotating machinery. Subsequently, Liu et al. [12] and Wang et al. [13] have found that the sensitive vibration frequency band of the sand (more than $10 \mathrm{KHz}$ ) is remarkable. However, the filtering of these characteristic frequencies is unable to completely filter out the flow background noises due to the widely distributed vibration frequency band of the sand.

Vibration power spectra corresponding to sand-carrying crude oil can reflect the relationship between sand production volume and the energy of impact signals. The ideal sand signals of power spectra present obvious multipeaks. A denoising method is selected to further extract the sand signals and reduce other background noise signals. First of all, Savitzky-Golay filter is selected to smooth the power spectra. It is defined as follows:

$$
Y_{j}=\sum_{i=-(m-1) / 2}^{i=(m-1) / 2} C_{i} y_{j+i} \quad \frac{m+1}{2} \leq j \leq n-\frac{m-1}{2} .
$$

The data consists of a set of $n\left\{x_{j}, y_{j}\right\}$ points $(j=1, \ldots, n)$, where $x_{j}$ is an independent variable and $y_{j}$ is an observed value. They are treated with a set of $m$ convolution coefficients with $C_{i}$ according to the expression. Secondly, the crude oil flow background noise is deducted according to the smooth curve results. Thirdly, symmetric zero area method is selected to extract the sand signals of power spectrum peak by peak searching. It is mentioned as follows:

$$
Y_{i}=\sum_{j=-m}^{m} C_{j} X_{i+j}, \quad \sum_{j=-m}^{m} C_{j}=0, C_{j}=C_{-j} .
$$

$X$ and $Y$, respectively, are input and output dates, $C_{j}$ is the window function of symmetric zero area, and $W=2 m+1$ is the transformation width. Finally, the value of searched minimum peak is selected as final background noise due to the excellent capacity of weak peak searching [14]. The final sand vibration energy is equal to the searched multipeak values subtracting the minimum peak value.

2.2. Sand Production Monitor Step. Since Bohai bay is a typical unconsolidated sandstone reservoir and easy to produce sand [15], Bo Zhong oil production platform is chosen as the monitoring testing areas of sand production in Bohai bay. The size of sands mainly ranges from $73 \mu \mathrm{m}$ to $311 \mu \mathrm{m}$. Four typical wells are selected as sand production monitoring wells according to the well reports. Table 1 shows the major parameters of these wells.

In the process of sand production monitoring, vibration signals are generated by sand-carrying flows and sent to the charge amplifier; then the computer receives digital signal converted by analog signal through multichannel high-speed data acquisition card. The collected sand production signals are processed and displayed by signal handler. Vibration signals are specially detected with high frequency piezoelectric 
TABLE 1: Major parameters of test wells.

\begin{tabular}{lcccc}
\hline Well & Flow temperature $\left({ }^{\circ} \mathrm{C}\right)$ & Moisture content $($ Vol. $\%)$ & Flow velocity $(\mathrm{m} / \mathrm{s})$ & Sand content $($ Vol.\%) \\
\hline A5 & 56.2 & 78 & 2.21 & 0.01 \\
A15 & 55.6 & 40 & 0.69 & 0.00 \\
A25 & 53.9 & 52 & 0.72 & 0.02 \\
A45 & 56.0 & 60 & 2.17 & 0.00 \\
\hline
\end{tabular}

acceleration sensor made by PCB Company (mode 357B03). As for this vibration sensor, the sensitivity is $10 \mathrm{pc} / \mathrm{g}$ and the frequency range is $0-18 \mathrm{KHz}$. It is due to the contradiction between sensitivity and bandwidth that the vibration sensor is employed. The signal handler is set to acquire vibration waveforms at a sampling rate of $50 \mathrm{KHz}$, and the sampling points are 8192. The window function is Gaussian window and the period of data refresh is $5 \mathrm{~s}$. Besides, a $20 \mathrm{KHz}$ low pass filter is set to reject the high error percent of signals, which are caused by the out of maximum ratings of sensor in this acquisition system.

\section{Results and Analysis}

3.1. The Signal Analysis of Crude Oil Flow. Investigations in the time-frequency domain were undertaken with short-time Fourier transform (STFT) analysis, which employed a 128point FFT length and Blackman window type. Besides, a $2 \mathrm{KHz}$ high pass filter was set to eliminate most of mechanical system background noise. Analysis results of the typical four wells as Table 1 mentioned are shown in Figure 2.

The time-frequency plots (Figure 2(a)) for number A15 well without sand production show that the crude oil impact vibration frequencies are widely distributed, but the dominant frequency band mainly focuses on $2.5-7.5 \mathrm{KHz}$. It is evident that the frequency band between 10 and $15 \mathrm{KHz}$ is marked in solid white lines, where the energy intensity level is much lower than others.

The STFT analysis result of number A25 well (Figure 2(b)) shows that the crude oil vibration frequencies are also widely distributed. The limitation of energy intensity level within $10-15 \mathrm{KHz}$ marked with solid white lines is still higher, especially for time $0.043-0.058 \mathrm{~s}$ and $0.072-0.082 \mathrm{~s}$. In these two periods, there are obvious features of impact signal by time-domain analysis. The STFT analysis results illustrate that the same low frequency band as number A15 well is also generated. The abovementioned descriptions are the sand production features of number A25 well. The characteristic sand vibration frequency band appears coupling with sandcarrying crude oil flow impacting on the wall. So vibration sensor approaches can detect low intensity sand signals under relative high intensity crude oil flow signals.

Figure 2(c) shows the frequency spectrum results of number A45 well without sand production. The energy intensity level of the frequency band between 10 and $15 \mathrm{KHz}$ marked in solid white lines is almost zero. The detected vibration frequency bands are mainly distributed on other frequency bands like number A15 well with nonsand production.

The analysis results of number A5 well can be seen in Figure 2(d). The energy intensity level of the characteristic sand frequency band marked in solid white lines is high due to the existence of the sands in the oil-flow conveying pipeline. That is the phenomena of sand production, and the sand impacting signals are more sensitive to this characteristic sand frequency band. It can be seen that, in time $0.937-0.107 \mathrm{~s}$ and $0.128-0.134 \mathrm{~s}$, there are obvious crude oil flow impact signals by time-domain analysis. During these two time periods, sand-carrying flow accumulates over a high energy intensity level with frequency range of $11-15 \mathrm{KHz}$ caused by sand impact and $4-7 \mathrm{KHz}$ low frequency caused by oil flow impact. So it is much easier for vibration sensor to detect the sand impact signals in sand-carrying crude oil flow which possesses obvious impact features in time-domain.

The STFT analysis results of nonsand production wells number A15 and number A45 (Figures 2(a) and 2(c)) show that the flow frequency bands mainly focus on $2-7 \mathrm{KHz}, 8-$ $10 \mathrm{KHz}$, and $15-20 \mathrm{KHz}$, respectively. In order to reduce the interference of flow impact maximally, these frequency bands are set as interference frequency bands. As for the frequency band of $7-8 \mathrm{KHz}$, the energy intensity level is low. However, for this frequency band of sand production wells number A25 and number A5 (Figures 2(b) and 2(d)), the energy intensity level is low too. Besides, these low frequency bands are more sensitive to the oil flow impact. Therefore, comparing signals from the sand production wells (number A25 and number A5) with those from nonsand production wells (number A15 and number A45), obvious sand characteristic frequency band of $10-15 \mathrm{KHz}$ is observed. Furthermore, filter type has been set at band-pass frequency of $10-15 \mathrm{KHz}$ to maximally reduce the interference of flow impact vibration signals. After that, the power spectrum can be used to analyze the relationship between sand production volume in crude oil and vibration signals captured by sensors.

3.2. The Signal Analysis of Sand Production Volume. In experiments, Husin et al. [16] showed that the main factor affecting the vibration power spectrum amplitude was the speed of crude oil flow. So, two wells with almost equal flow speed were selected to better reveal the characteristics of sand production. A 100-point Savitzky-Golay filter method was used to extract the trend of the power spectra (the green and ultramarine lines in Figures 3-4). Symmetric zero area method was selected to extract the sand signals of peaks in power spectrum by peak searching.

Figure 3 shows the power spectra of number A5 well and number A45 well. It is clear that the result of A5 well possesses the characteristics of sand production. By the peak searching-denoising method, the peaks of power spectrum of number A5 well are extracted to further illustrate the results 


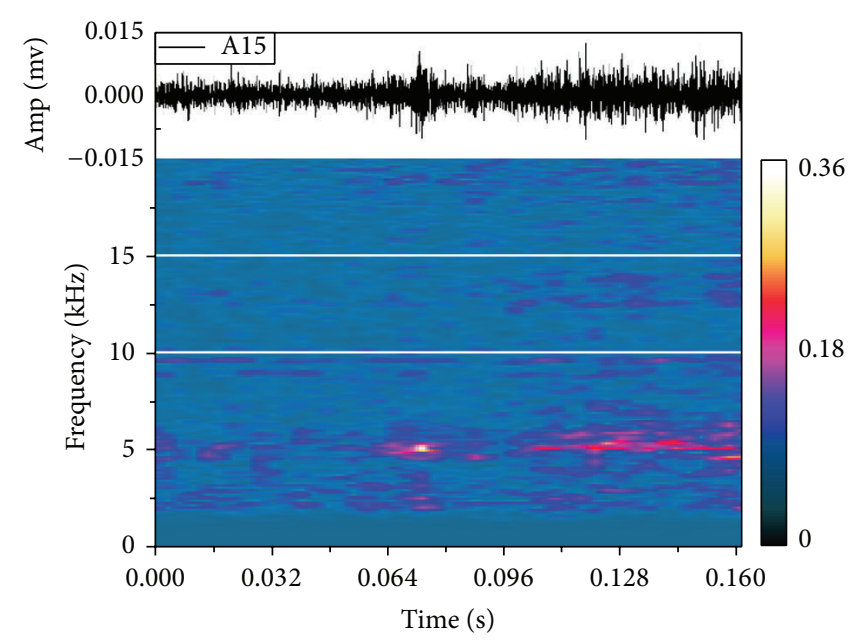

(a)

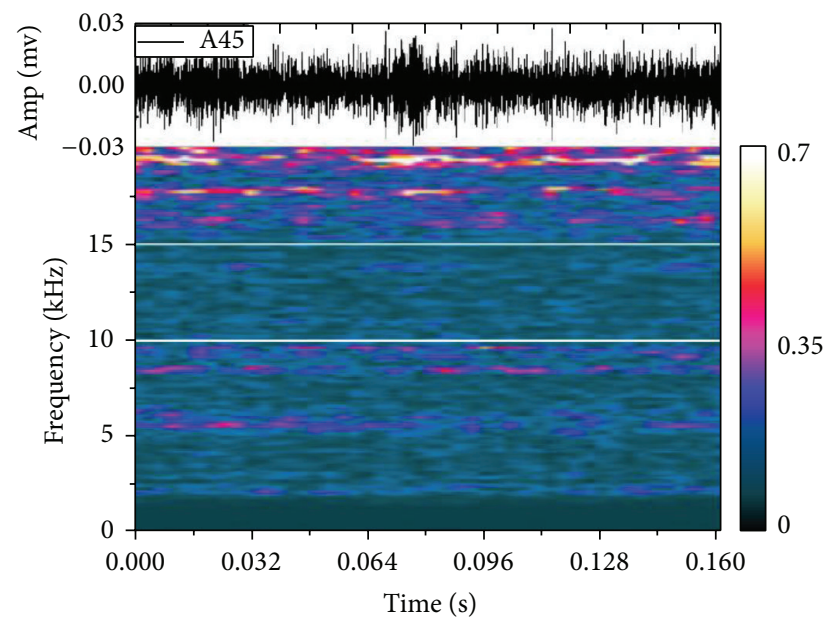

(c)

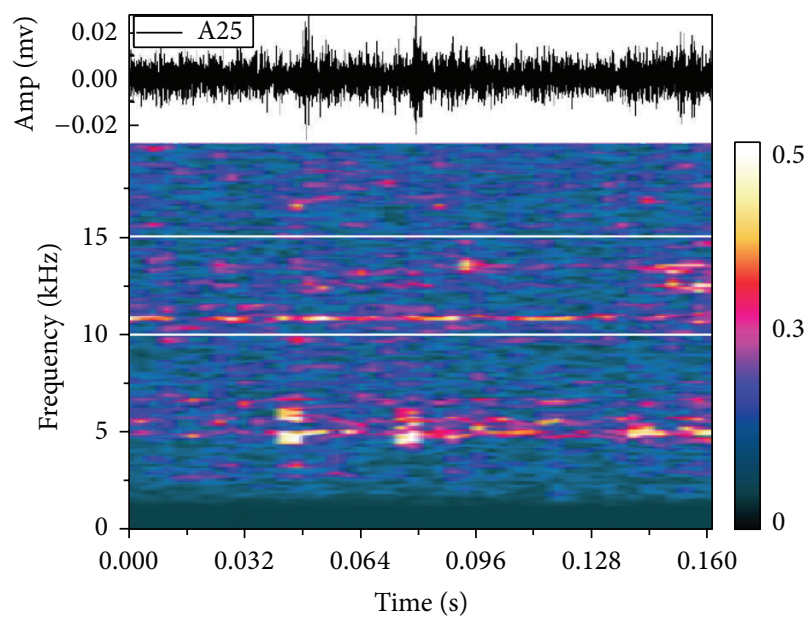

(b)

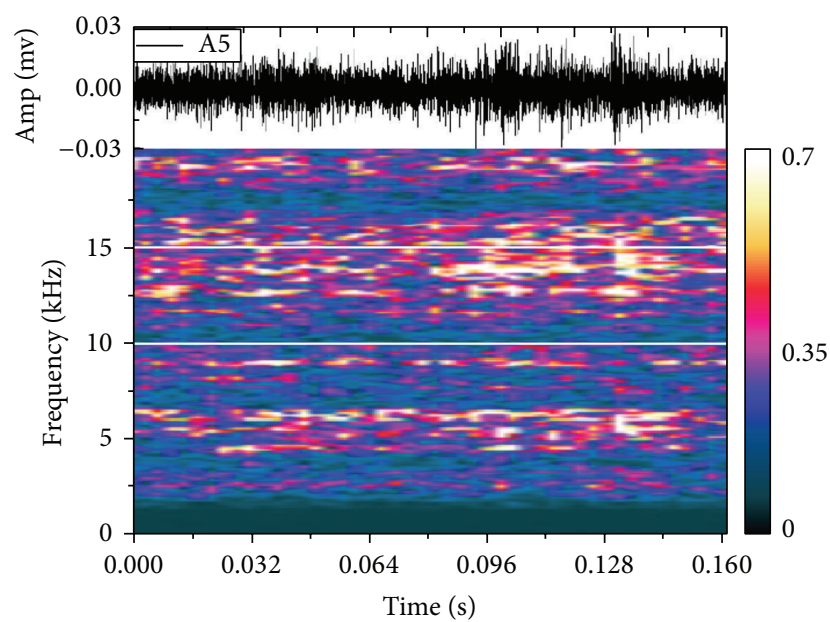

(d)

FIGURE 2: STFT analysis of sand production vibration signals: (a) number A15 well; (b) number A25 well; (c) number A45 well; (d) number A5 well.

of sand production volume. This result is shown in top right corner (the insert portion of Figure 3). The value of searched minimum peak is 375.33 . There are 61 peaks in number A5 well. Their integral value and average value are 16235.57 and 266.16, respectively. The power spectrum of number A45 well owns smaller undulations and has no obvious abrupt values compared to number A5 well, because there is no sand production in crude oil mining process. Comparing the trend of power spectra with different oil-flow velocities from the number A5 well and number A45 well, the mean values of number A5 well and number A45 well are 1102.07 and 949.54, respectively. These differences are mainly caused by the higher flow velocity of number A5 well compared with number A45 well. The statistical dispersions of number A5 well and number A45 well are $4.78 \%$ and $0.91 \%$, respectively. This higher percent of the number A5 well comes down to its characteristic of sand production.

Figure 4 presents a summary of the power spectra of number A25 well and number A15 well. The characteristic of sand production in number A25 well is evident, and these sand production multipeaks features are illustrated in top right corner (the insert portion of Figure 4). The value of searched minimum peak is 475.13 . There are 52 peaks in number A25 well. Their integral value and average value are 32576.56 and 626.47, respectively. The power spectrum of number A15 well has the features of nonsand production like number A45 well. Comparing the trend of power spectra with different oil-flow velocities from the number A15 well and number A25 well, the mean values of number A15 well and number A25 well are 285.38 and 714.44, respectively. These differences are caused by the lower flow velocity of number A15 well compared with number A25 well. Besides, a huge sand content gap between these two wells contributes to the difference of the power spectrum amplitude. The statistical dispersions of number A5 well and number A25 well are $3.35 \%$ and $6.64 \%$, respectively. This difference conforms to the characteristic of high volume sand production of number 25 well. 


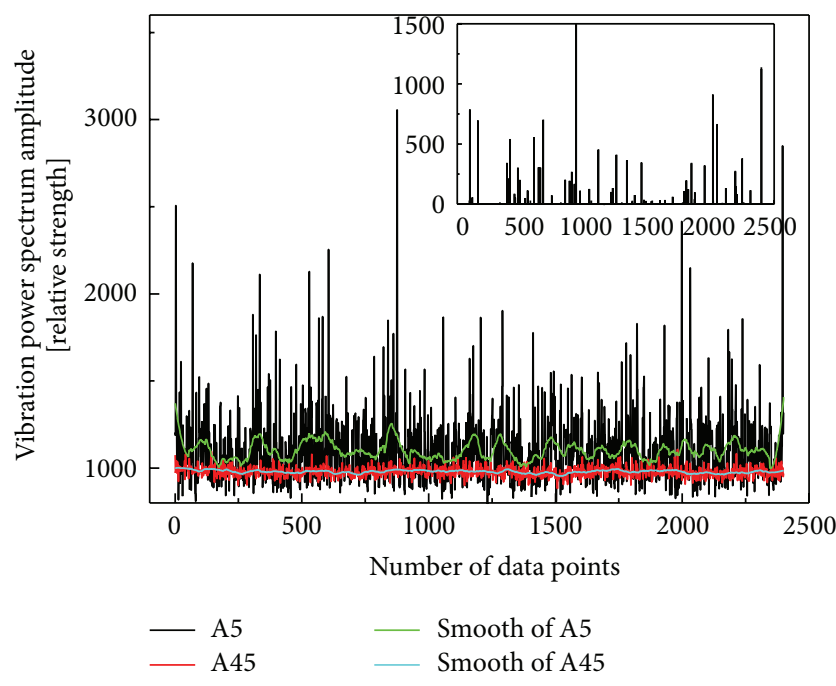

Figure 3: Comparisons of the power spectrum of number A5 well and number A45 well.

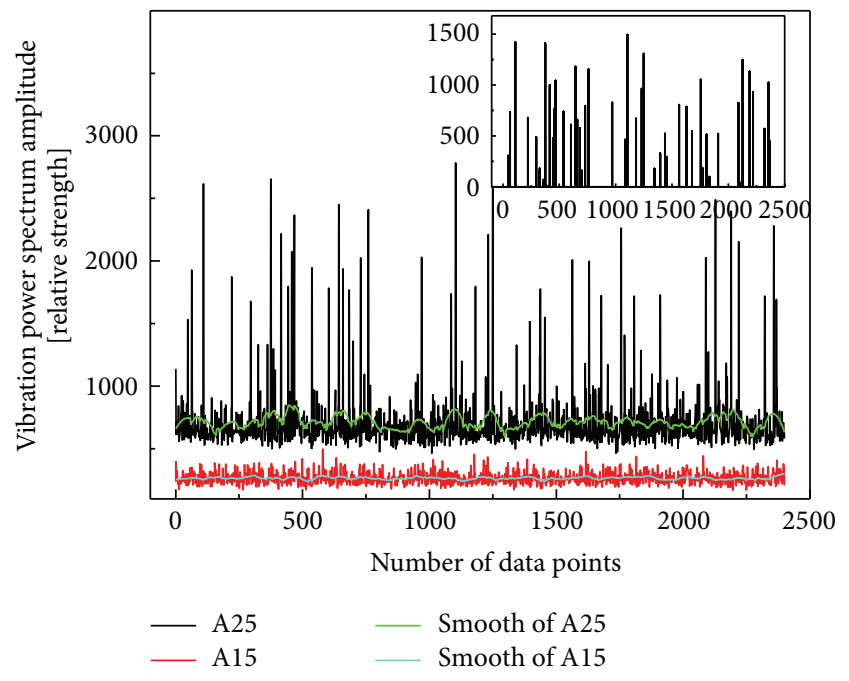

FIgURE 4: Comparisons of the power spectrum of number A25 well and number A15 well.

From Figures 3 and 4, the power spectrum amplitude shows that the vibration sensor approaches can successfully detect the sand production features in real-time. The number A5 well and number A25 well possess obvious multipeak feature, and the amplitudes are higher compared to number A45 well and number A15 well. Each peak signal reflects a trend of the sand production volume, and the integral value of peaks illustrates the trend of total sand content. The results show that the integral value and average value of number A25 well are, respectively, 2 times and 2.3 times of those of number A45 well. These sand production monitoring results agree well with the measured data in Table 1. In other words, the sand production volume of number A25 well is 2 times of that of number A 45 well. Comparing the trend of power spectra with these four typical wells, the mean value of number A45 well is 3.3 times of number A15 well. This result accords with the
3.1 times caused by different flow velocities. As for the same flow velocity level of wells, the features of sand production can lead to a higher statistical dispersion. Therefore, flow velocity affects the power spectrum amplitudes but does not affect the monitoring of sand production.

Based on the above results, sand production vibration signals of four typical wells were successfully detected by special wideband vibration sensor in Bohai oil production platform. The characteristic sand frequency band was discovered by time-frequency analysis. Peak searching-denoising method successfully extracted the characteristic sand signals from band-pass filtered power spectrum and maximally reduced the background noise of crude oil flow. The characteristic multipeak of power spectrum was used to illustrate the sand production volume signals, which was consistent with actual results. Accordingly, this method would be helpful to apply the vibration sensor technology to monitor the sand production in offshore oilfield production.

\section{Conclusions}

(1) A special wideband vibration sensor was selected to acquire sand production signals. Time-frequency analysis, a characteristic sand frequency band digital filter method, and a peak searching-denoising method were used to successfully extract the sand impact signals from crude oil background noise.

(2) By using these vibration sensor approaches, obvious differences in time-frequency domain and power spectrum between sand production well and nonsand production well can be observed. The power spectrum amplitude of sand production well possesses the characters of sudden changes and sharp increases. The time-frequency domain has the features of high energy intensity in the characteristic sand frequency band.

(3) The sand production volume has a good correlation with the obtained power spectrum amplitude of the signals, and it is also consistent with the results of field measurement. Vibration sensor approaches can effectively monitor the sand production in realtime during the process of oil production in Bohai production platform.

(4) These nonintrusive vibration sensor approaches not only provide a low-cost sand production monitoring method but also lay the foundation for the mathematical model studies of real-time and accurate sand production volume.

\section{Conflict of Interests}

The authors declare that there is no conflict of interests regarding the publication of this paper. 


\section{Acknowledgments}

The authors thank the key project of the Science and Technology Ministry of China (2011ZX05024-002-010, 2011ZX0524003-005, and 2011ZX05057-002-006) and the Fundamental research funds for the Beijing Radiation Center (620010567).

\section{References}

[1] A. Nouri, H. Vaziri, E. Kuru, and R. Islam, "A comparison of two sanding criteria in physical and numerical modeling of sand production," Journal of Petroleum Science and Engineering, vol. 50, no. 1, pp. 55-70, 2006.

[2] P. G. Ranjitha, M. S. A. Pereraa, W. K. G. Pereraa et al., "Sand production during the extrusion of hydrocarbons from geological formations: a review," Journal of Petroleum Science and Engineering, vol. 124, pp. 72-82, 2014.

[3] Z. Wang, H. Tian, J. Deng et al., "Improving well productivity through sand control," Oil Drilling Production Technology, vol. 28, pp. 59-63, 2006.

[4] H. S. He and Q. Zhang, Sand Control Theory and Application of Oil \& Gas Well, China Petrochemical Press, Beijing, China, 2003, (Chinese).

[5] L. C. B. Bianco and P. M. Halleck, "Mechanisms of arch instability and sand production in two-phase saturated poorly consolidated sandstones," in Proceedings of the SPE European Formation Damage Conference, Expanding Horizons, pp. 185194, The Hague, The Netherlands, May 2001.

[6] E. Khamehchi, I. Rahimzadeh Kivi, and M. Akbari, "A novel approach to sand production prediction using artificial intelligence," Journal of Petroleum Science and Engineering, vol. 123, pp. 147-154, 2014.

[7] M. Ibrahim and T. Haugsdal, "Optimum procedures for calibrating acoustic sand detector, gas field cage," in Proceedings of the SPE Canadian International Petroleum Conference, SPE 2008-025, Calgary, Canada, June 2008.

[8] N. A. Braaten, T. J. Blakset, and D. Morton, "Experience from topside and subsea use of the erosion based sand monitoring system," in Proceedings of the SPE Annual Technical Conference and Exhibition, SPE 30644, pp. 147-157, Dallas, Tex, USA, October 1995.

[9] N. A. Braaten, R. Johnsen, G. Sirnes et al., "A new concept for sand monitoring: sand probe based on the ER technique," in Proceedings of the SPE Offshore Technology Conference, SPE 6985, Houston, Tex, USA, May 1992.

[10] N. C. Hii, C. K. Tan, S. J. Wilcox, and Z. S. Chong, "An investigation of the generation of Acoustic Emission from the flow of particulate solids in pipelines," Powder Technology, vol. 243, pp. 120-129, 2013.

[11] Q. B. He, J. Wang, F. Hu, and F. Kong, "Wayside acoustic diagnosis of defective train bearings based on signal resampling and information enhancement," Journal of Sound and Vibration, vol. 332, no. 21, pp. 5635-5649, 2013.

[12] G. Liu, P. T. Liu, J. L. Han et al., "High frequency vibration signal acquisition system used for sanding monitoring in oil well," Petroleum Geology and Recovery Efficiency, vol. 20, pp. 108-110, 2013.

[13] K. Wang, Z. G. Liu, G. Liu et al., "Vibration sensor approaches for sand detection in oil-water-sand multiphase flow," Powder Technology, vol. 276, pp. 183-192, 2015.
[14] J. F. Pang, G. F. Zheng, and X. F. Hou, “The symmetric zero-area conversion method for peak-seeking," Atomic Energy Science and Technology, vol. 21, pp. 270-279, 1987.

[15] P. Li, J. G. Deng, W. L. Zhao, and J. Y. Zhao, "The optimization of sand control completion in bohai bay," Petroleum Science and Technology, vol. 30, no. 16, pp. 1704-1714, 2012.

[16] S. Husin, A. Addali, and D. Mba, "Feasibility study on the use of the Acoustic Emission technology for monitoring flow patterns in two phase flow," Flow Measurement and Instrumentation, vol. 33, pp. 251-256, 2013. 

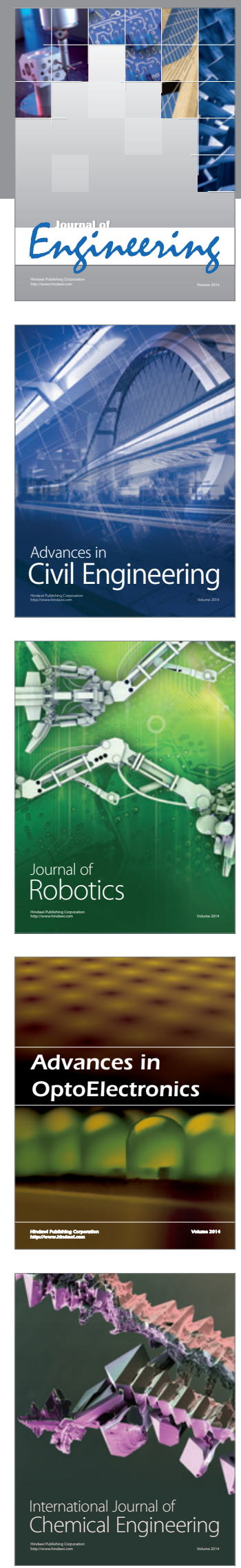

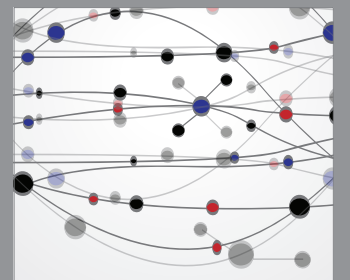

The Scientific World Journal
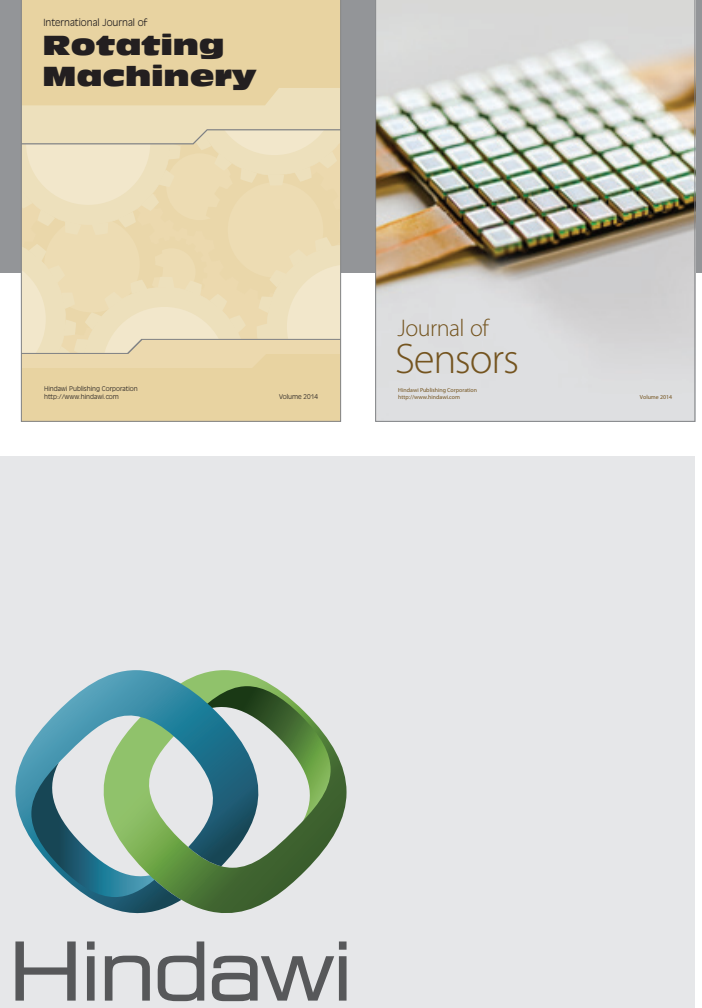

Submit your manuscripts at http://www.hindawi.com
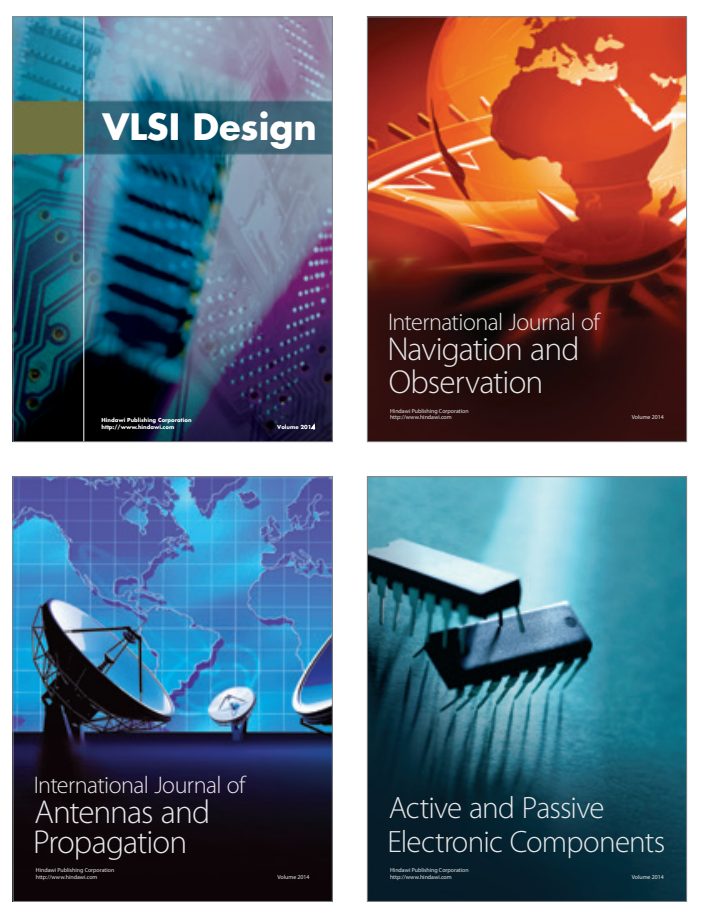
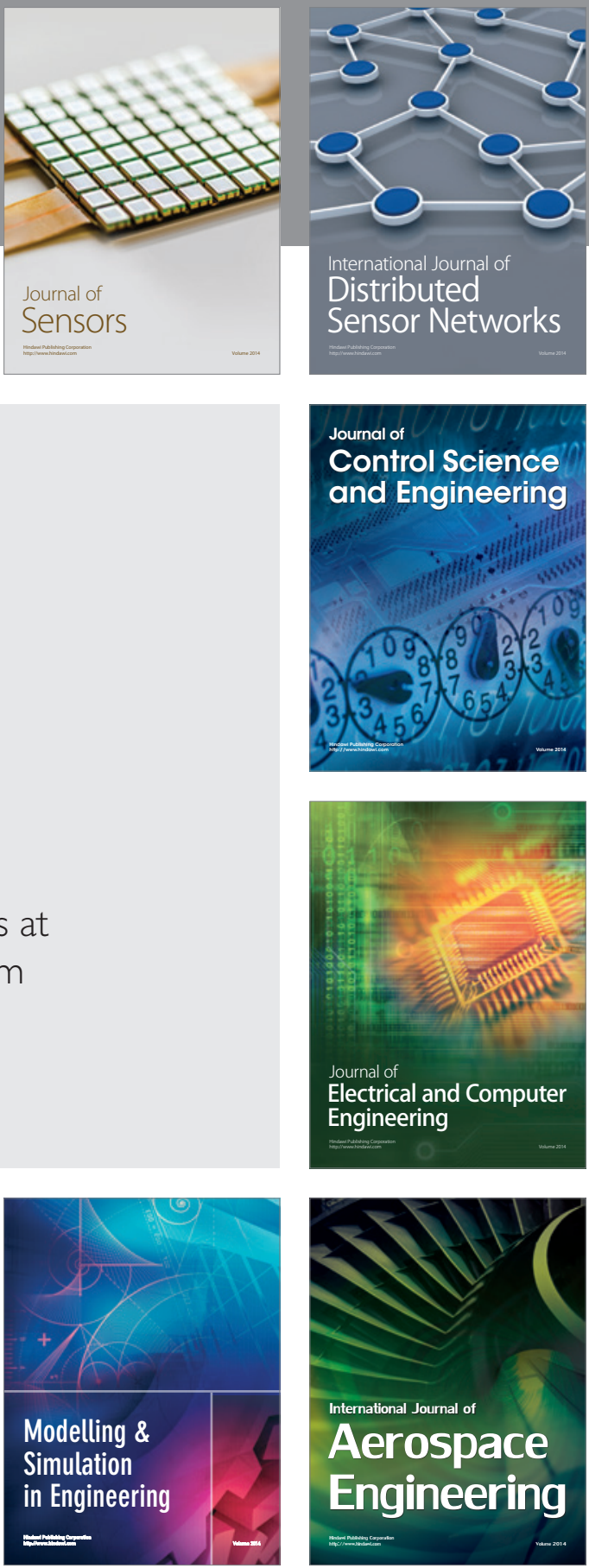

Journal of

Control Science

and Engineering
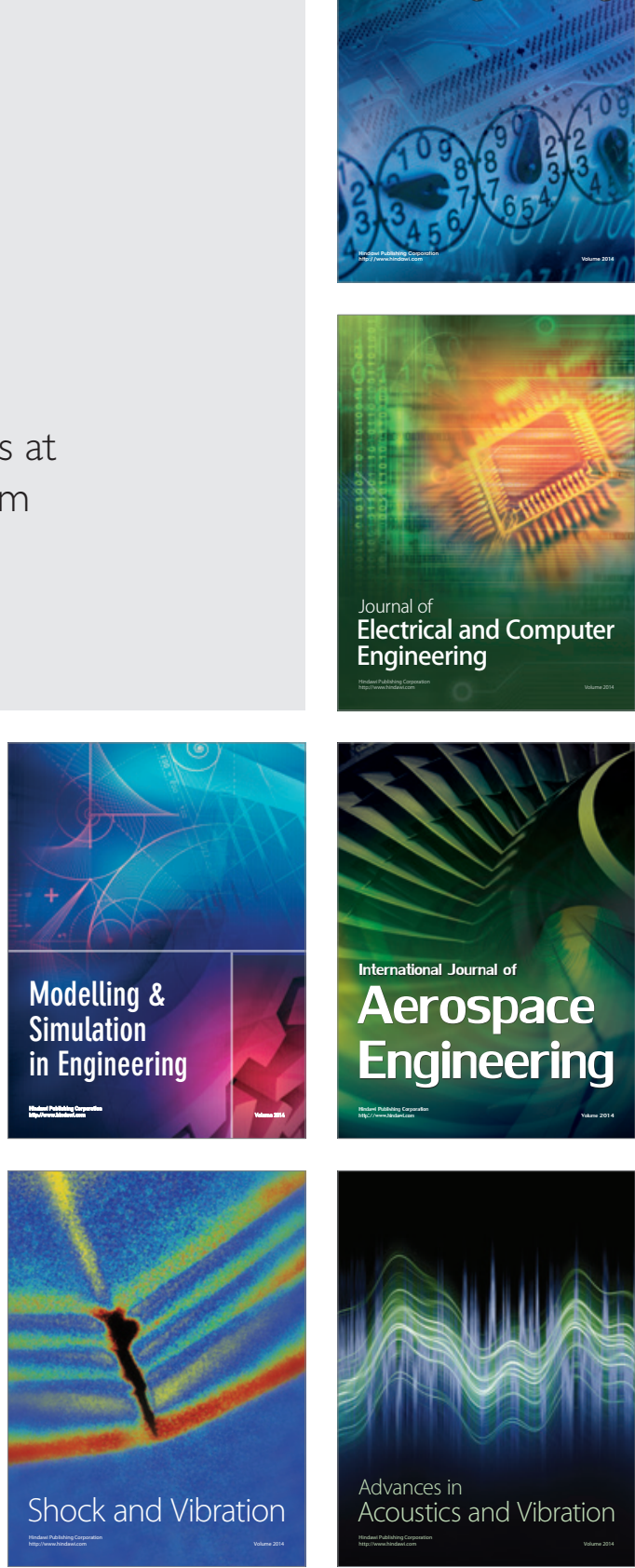